\title{
LOGOS POST-LOCUCIONARIO
}

\author{
Por Fabián LUDUEÑA ROMANDINI
}

\section{I.}

La mujer que ocupa el semblante de Eva le dice al hombre que hace las veces del semblante de

Oscar en Holy Motors, el filme de Leos Carax, "on a veingt minutes pour rattraper 20 ans (tenemos veinte minutos para ponernos al día con 20 años)", es decir, el tiempo durante el cual no se han visto. Tanto más decisiva aún se torna la frase cuanto que el fortuito encuentro en las calles de París no volverá a repetirse: "sans doute, on ne se verra plus jamais (sin duda, nunca jamás volveremos a vernos)”.

Pocas frases podrían restituir, con más acuidad, el espíritu de nuestro tiempo. Por cierto, para que la expresión se torne verdaderamente inteligible no debe entenderse en el singular de la relación efectivamente descripta en el filme. Al contrario, se impone el gesto de convertirla en el enunciado existencial que podría proferir cualquier habitante de una megalópolis del siglo XXI. Tampoco deben interpretarse las circunstancias materiales como un simple impedimento circunstancial (falta de tiempo debida a las misiones asignadas de los personajes). Al contrario, la escena expresa el tiempo estructural en el que una vida puede relatarse en el siglo presente.

En este sentido, el filme alcanza, en la contingencia, una condición universal: la biografía del siglo XXI no necesita de más de 20 minutos para poder dar cuenta de los trazos fundamentales - generalmente dolorosos, pero indignos de un relato extendido en el tiempo- del devenir de un hombre. Por supuesto, en estas nuevas condiciones, no hay posibilidad de recobrar el tiempo perdido. A lo sumo, es posible inscribir otros retazos biográficos en un continuum anónimo de experiencias análogas que no llegan a constituir la Historia sino tan sólo una referencia homologable que tiene, siempre, un sentido incompleto pero suficiente en su precariedad.

Esto no es equiparable al gesto de los Antiguos que, respecto de las vidas, también podrían parecer inclinados a la brevedad expositiva. Sin embargo, esta característica no era el resultado de una propiedad de la materia narrativa sino, al contrario, de una decisión consciente de autores que, como Plutarco, deseaban dar cuenta de la forma de una vida (bíos) a partir de las "pequeñas cosas (pragma brachú)" que se pueden esconder tanto en 
una acción épica como en una anécdota menor. La búsqueda de una constelación vital exigía una economía restringida de palabras que debían extraerse de una plétora de experiencias vividas y de innumerables leyendas y relatos.

La situación contemporánea es por completo diferente porque un cambio de envergadura se ha introducido en la experiencia de la propia vida. La postulación de un universo infinito por parte de la ciencia moderna ha transformado, en grado eminente, cualquier concepción de la propia vida individual. Siendo consecuentes con la ciencia moderna, ningún ser humano es más que un punto en un universo infinito el cual lo torna, al menos en un primer momento, en completamente idéntico a los otros. Desde el punto de vista del nuevo universo, ningún ser humano resulta especialmente importante y es potencialmente transformable en una cifra. La estadística es la ciencia que más rápidamente ha comprendido el gesto: no sólo por el hecho, repetido hasta el cansancio, de que trata a las personas como números (¿de qué otra forma podría hacerlo?) sino más bien, y esto resulta capital, porque su efectividad reposa, como ha sido señalado, en su capacidad probada de predecir la conducta de millones de seres humanos basándose en muestras de tamaño restringido a pocos miles.

Lo decisivo, entonces, no es tan sólo que un individuo A equivalga a un individuo B sino más bien que la conducta, los pensamientos, las acciones de A (relevados estadísticamente) pueden predecir los de X millones de individuos no encuestados. La encuesta, en ese sentido, no estudia a quien es entrevistado, sino con toda propiedad, a quien no lo es. Por lo tanto, como ha sido notado, negarse a participar de una encuesta equivale, en estricto rigor, a transformarse en el verdadero objeto de la estadística. Se dirá que, políticamente, se trata de una perversión numérica de la matemática propiciada por un universo infinito. Sin embargo, ninguna diatriba contra la estadística debe esconder el hecho esencial: la efectividad de la encuesta es sólo concebible bajo la ciencia de un universo infinito donde los hombres desarrollan un estilo de vida que, por más diverso que quiera presentarse, es ineluctablemente absorbido en una ley subyacente que lo torna un punto predecible y, por lo tanto, también absolutamente prescindible en el conjunto del planeta.

Esta condición efectivamente moderna del hombre lo ha condenado a ser un mero simulacro en un mundo donde la apariencia, por otra parte, es considerada como una superficie engañosa del Ser que debe ser trascendida hacia sus manifestaciones precisas en la ciencia del número. Que el hombre sea sólo un semblante (en una escala de agregación numérica, el fenómeno fue bautizado, con cierto equívoco, como “sociedad del 
espectáculo"), ha desatado la crítica: justa a veces, inconsistente muchas veces. En cualquier caso, se ha demorado gravemente la comprensión del elemento esencial: en el universo moderno, el hombre no puede sino ser un simulacro. Se trata, pues, de un teorema de existencia y no de una alienación del Ser.

El fenómeno era inevitable y está implícito en el pasaje de lo que podríamos denominar la "liturgia del Ser" (el Dios infinito de la escolástica medieval objeto, asimismo, de todas las imágenes piadosas y de la praxis laudatoria) al "infinito en el Ser" que se refleja en una transferencia de propiedades (que algunos gustan denominar "secularización"). Un testimonio precioso lo provee un importante escolástico del siglo XVII: "Dico itaque cum auctoribus secundae opinionae Deum esse in infinitis spatiis imaginariis extra coelum in immensum diffusis" (COMPTON-CARLETON, Thomas, Philosophia universa, Antverpiae: apud Iacobum Meursium, 1649, sectio IV, col. 2, p. 337). El atributo de la infinitud, propio de los espacios extra-cósmicos de la majestad divina, son transpuestos al Universo en su totalidad como nuevo hábitat de un hombre, por consiguiente, propiamente des-centrado.

La matematización del Infinito deberá esperar, no obstante, a Cantor (se discute si su teoría cambia el escenario: nuestra opinión es afirmativa). La relatividad de Einstein, por su parte, tornará obsoleta cualquier discusión metafísica basada en el trillado problema del heliocentrismo o geocentrismo del sistema solar. Un problema menor que, sólo bajo la óptica del Infinito, adquiere su verdadero significado al mismo tiempo que pierde toda entidad teórica de fuste (me remito aquí a las páginas, demasiado a menudo pasadas por alto, que Hannah Arendt ha escrito al respecto). En el mismo movimiento en que las imágenes eran reservadas a la glorificación del Ser infinito de Dios, su traspaso multiplicado al Universo como nuevo absoluto material, producen la transmutación metafísica del hombre en un simulacro inserto en un mundo enteramente litúrgico que exalta a la imagen qua imagen y donde la vida humana resulta estructuralmente indistinguible de un conjunto organizado de pixeles. El proceso, por cierto, marca una mutación civilizacional (y, por lo tanto, metafísica) de alcances impredecibles. Como toda mutación de la cual no hay retroceso posible, sólo queda el ejercicio de la comprensión.

En lugar de lamentarse, hay que asumir con radicalidad la nueva situación. En ella podrá quizá aparecer lo que algunos llaman, en un acto de valentía que ya veremos si puede transformarse en una facticidad plausible, una singularidad. Sin embargo, para que esto sea posible, habrá que asumir la apuesta del universo infinito y la subjetividad que éste propone. Que el hombre no sea más que un punto matemático supone, sin lugar a duda, el verdadero final del Humanismo tal y como, en diversas formas, fue concebido, por lo 
menos, hasta los Tiempos Modernos. No deja de ser una ironía, por cierto, que los grandes astrónomos de la Modernidad hayan sido, todos ellos, los últimos grandes defensores y productos del Humanismo.

Antes de poder pensar, ciertamente, qué singularidad puede construir el hombre cuando es concebido como una entidad numérica (lo cual implica pensar, nuevamente, qué es un número), hay que tomar en cuenta el hecho de que, muy probablemente, la denominación Homo sapiens no haga alusión, hoy en día, sino a una especie en extinción (sino ya subjetivamente extinta).

Como ya lo entrevía Kant, lo único que se resiste a ser subsumido bajo la Ley (tanto científica como moral) es el dolor. Desde este resto aparentemente tan precario, la filosofía podría aspirar a despertar de su verdadero sueño dogmático y asumir todas las tareas que ha dejado en manos de la antifilosofía: la primera de ellas, descifrar si existe una forma de vida completamente nueva que aspire a querer ser dicha en ese dolor que se constata silenciosamente en todos los habitantes del orbe. Empero, como condición de posibilidad de tal pregunta, la filosofía deberá abandonar, primeramente, lo que hemos llamado el "principio antrópico" que subyace en la interpretación de la antigua concepción del hombre y el cosmos en la historia de la metafísica occidental. El "destinatario" que pueda recibir, entonces, las fuerzas del pensamiento y del lenguaje habrá mutado de un modo decisivo.

II.

La ciencia lingüística, apoyada en el paradigma científico moderno, se ha asentado, entre otros, en dos axiomas fundamentales: a)- las condiciones del intercambio lingüístico están ausentes en el mundo animal (Benveniste) y b)- la interlocución implica la existencia de una comunicación que puede ser pensada según un modelo matematizable o, por lo menos, codificable (Jakobson). Un corolario del segundo axioma señala el "peligro" de transformar la intercomunicación humana en mera "información física" (Jakobson inspirado por MacKay). El segundo axioma, como veremos, corre el riesgo de saturar al primero. Sin embargo, debemos hacer notar un serio retroceso en la historia del pensamiento, desde una perspectiva filosófica, respecto del primer axioma. De hecho, Sexto Empírico (Esbozos pirrónicos I, 74) ya establecía que no era "inverosímil (apeikòs)" que los animales hablen pero que los humanos no pudiésemos entenderlos. Este argumento será retomado por Montaigne (Essais, II, 12) quien añadirá que si bien nosotros no comprendemos el lenguaje de los animales, la situación inversa es igualmente plausible. 
Y el propio Plutarco concede tanto en su De sollertia animalium (961C) como en su Bruta animalia ratione uti (992C) que los animales tienen lenguaje-razón (lógos) y comprensión (súnesis).

Si la vida lingüística de los hombres parece dejar vacío todo espacio de interlocución directa para disolverse en diversos lenguajes informáticamente mediatizados (con los consiguientes cambios sintácticos y morfológicos asociados a dicho proceso), la destrucción de la biosfera terrestre resulta de la condición asociada de negarles a los animales toda capacidad "sintáctica" (como señalaban antaño los estoicos y hoy la lingüística chomskiana). En el universo infinito de la ciencia moderna, cuando el hombre es pensado como punto matemático, entonces el "destinatario" de la comunicación es indistinto y, por lo tanto, se torna verdaderamente superfluo. En cierto sentido, el hombre pierde su capacidad de transmisión de un legado a partir de un lenguaje entendido como vehículo de una voz de sabiduría al mismo tiempo que toda su capacidad sintáctica se transforma en información que, retransmitida constantemente a escala global, se troca en pura comunicación desprovista de significación respecto de una herencia compartida.

Mientras tanto, el secreto del lenguaje de los otros animales se escapa por completo al animal humano y, junto con él, perece definitivamente el mundo en el cual la Voz tenía un correlato en la transmisión de alguna forma de Historia que constituyese un sentido para la perpetuación de la especie. Para el hombre ya no hay destinatario humano de su discurso y los otros animales ahogan su lenguaje en la incomprensión. Y cuando un hombre habla, ninguna vida necesita más de veinte minutos para ser narrada. Ningún destinatario necesita ya, nada más, que las informaciones de una identidad que puede ser reducida a rasgos formalizables y predecibles. En este sentido, se torna una realidad el "peligro" del segundo corolario de la lingüística: reducido a información, el lenguaje "humano" se torna cada vez más indistinguible de la codificación de la naturaleza y del mundo físico.

Los últimos hombres evocados por Nietzsche se congratulaban de poder decir: "Wir haben das Glück erfunden (nosotros hemos inventado la felicidad)”. El filósofo alemán se burlaba de ellos. Sin embargo, sólo hoy estamos en condiciones de medir la justeza de sus palabras: no sólo porque la felicidad de esos hombres sea pequeña e insignificante (como pensaba Nietzsche) sino porque ya no existe. Estamos, por así decirlo, transitando la salida de la especie Homo sapiens mientras que su relevo aún no ha llegado. Ya nadie pretende hoy la felicidad (más allá de los discursos indulgentes de la época) porque los últimos hombres saben que han perdido esa posibilidad junto con el final de la interlocución. Las palabras 
de los últimos hombres carecen de destinatario: nadie las escucha (ningún Otro, ni un dios, ni un objeto poético, ni siquiera el propio hombre puede ya tener un diálogo consigo mismo).

Los últimos hombres creen hablar pero ya no lo hacen. Su lenguaje puede traducirse en una formalización donde la palabra humana se confunde con el lenguaje informacional del mundo físico en tanto matemáticamente expresable. Con el fin del parlêtre que sólo habla un lenguaje cuyo dominio pierde cada día más hasta que se torne completamente opaco y anodino, la ineluctable extinción de los últimos hombres marcará el paso hacia una radical subversión del papel primordial hasta ahora detentado por el Homo sapiens en el acceso a la esfera de un Lógos que lo sobrevivirá. Acaso los hombres por venir logren, tal vez, escuchar por primera vez (de forma tan espontánea como en el Maroccus Extaticus) el lenguaje de los animales o de las piedras y los secretos que se esconden en sus pliegues. El hombre por venir deberá convertirse en el "destinatario" de un Lógos articulado de forma completamente inédita.

Para que esto tenga lugar, ¿será necesario, como escribió Osip Mandelstäm al hablar de la poesía de Sologub, que pasen “cientos de años” todavía? 